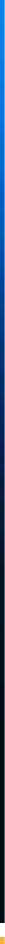

EIDOS, 4

Marzo-agosto 2011, 51-58

ISSN:1390-499X

elSSN:1390-5007

\title{
LAS FORMAS MODERNAS DE PRESENTACIÓN DE LA INFORMACIÓN SOBRE LOS PROYECTOS DE INNOVACIÓN: TEORÍA Y PRÁCTICA
}

A. Maltseva, S. Frolov ${ }^{1}$, Universidad Estatal del Sur-Oeste de Rusia, Kursk

Recepción/Received: 2011-02-11

Aceptación/Accepted: 2011-07-14

Publicado/Published: 2011-08-05

Resumen - - En el trabajo se examinan formas modernas para la representación de la información sobre los proyectos de innovación. La atención especial es concedida a los aspectos claves de la visualización de la información científico-técnica, incluso con el uso de las tecnologías multimedia.

Palabra Clave -Información, Proyectos, Innovación

Abstract -At work, there are some ways of presenting information about innovative projects which are examined. Special attention is given to key aspects of scientific and technical information visualization, including use of multimedia techniques.

Keywords -Information, projects, innovation.

1 Sergey Frolov; estu9235@yadex.ru; Universidad Estatal del Sur-Oeste de Rusia. 


\section{INTRODUCCIÓN}

La etapa actual de desarrollo de las principales potencias mundiales, se caracteriza como un período de tránsito a la economía del conocimiento, cuya prioridad primordial consiste en el incremento de las investigaciones y desarrollo de áreas estratégicas en la ciencia, la técnica y las tecnologías.

El análisis demuestra un aumento del gasto para las investigaciones y desarrollo en el sector estatal y privado de la mayoría de las economías mundiales, que exige la elaboración y la sistematización de métodos, para la selección de las propuestas de innovación y de nuevas líneas de investigación, cuyo financiamiento es más oportuna.

El problema actual es del perfeccionamiento de los accesos, mecanismos, medios y formas de representación de la información científica, el crecimiento de la atención a la cual refleja ciertas tendencias objetivas del aumento del rol de los procesos informativos en el desarrollo de la sociedad. La información, en primer lugar científica, se hace poco a poco por el factor potente de la intensificación de la producción pública, del aumento en su eficiencia y del progreso de la sociedad en general.

\section{Los accesos científicos generales en la presen- tación de la información}

La presentación de los resultados científicos e ideas de innovación se realiza tradicionalmente en forma de informes científicos, publicaciones, presentaciones hechas en el computador, que incluyen la combinación de la información textual, simbólica y gráfica determinada por los siguientes factores:

- la conformidad a las exigencias del público objetivo y la comunidad científica;

- los rasgos psicofisiológicos en la percepción de la información por la persona.

Las investigaciones sobre la forma de la presentación de la información científica se consideran como la dirección конвергентное, fundada en la interacción interdisciplinaria de la informática, psicología general y social, semiótica (ciencia sobre los signos y los sistemas significativos) e infografica (ciencia sobre la representación visual de la información). En las secciones especiales de las ciencias indicadas están presentados los resultados de las investigaciones teóricas y aplicadas que fundamentan la necesidad de la combinación de la información textual y gráfica, también los rasgos cuantitativos y cualitativos de tal combinación.
En la semiótica está introducido el término "texto creolizado "-el fenómeno lingüístico visual especial que caracteriza la información, que consta de dos partes no homogéneas- verbal (de lengua /del discurso) y no verbal (que pertenece a otros sistemas significativos, incluso a iconos, es decir arte plástico), que forma una influencia visual completa, compleja pragmática que actúa sobre el destinatario [3].

El componente icónico del texto puede ser presentado por las ilustraciones (fotografías, dibujos), esquemas, tablas, imágenes simbólicas, fórmulas etc.

La imagen es una de las formas de la comunicación, que juega un papel importante en la presentación de las ideas, capaz de agilizar el sentido y al mismo tiempo entregar la información necesaria. Las imágenes hacen la información más atractiva y convincente, sus trazos competentes son capaces de sustituir considerablemente gran material textual que se usa efectivamente en el negocio editorial.

La difusión rápida de los procesos de la visualización está vinculada a la globalización del mundo, el crecimiento de la intensidad de los contactos distintos en la economía, la política, la cultura, la formación, la necesidad de la compresión mutua rápida y la interacción que permite hablar sobre un nuevo fenómeno global - el tránsito gradual de "la civilización textual" a "la civilización de las imágenes" [4].

Según la propuesta de Manuel Lima se puede dividir los proyectos de la visualización de la información en los que ponen en primer lugar la funcionalidad, y los que prefieren en primer lugar la belleza y la estética, llamadas como el arte informativo. Los proyectos indicados deben coexistir, puesto que pueden adoptar mucho uno de otro por medio de "la polinización cruzada" de las ideas, métodos y técnicas [2].

La labor principal del texto consiste en abastecer al lector o al espectador las condiciones óptimas para la comprensión y la interpretación. Cooperando uno con el otro, los textos verbal e icónico abastecen la integridad y la coherencia del texto semiótico, su efecto comunicativo, ya que la combinación de los mensajes de códigos diferentes se complementan y explican mutuamente[3].

Sin embargo el científico U. Eko notaba, que el sentido del signo icónico no siempre es tan claro, como piensan, y eso se confirma en donde en la mayoría de los casos este 
viene acompañado de su firma; inclusive conociéndose, el signo icónico puede ser interpretado ambiguamente y exige la fijación con el texto verbal.

Los textos creolizados pueden ser clasificados en dos grupos [3]:

- los textos con parcial creolización, o sea los componentes verbal y el icónico entran en las relaciones iguales, cuando la parte verbal es relativamente autónoma los elementos plásticos del texto se encuentran facultativamente, es decir que pueden ser quitados sin daño considerable para la comprensión del sentido del mensaje (los textos periodísticos, de divulgación científica y artísticos);

- los textos con creolización completa - entre los componentes verbal e icónico se establecen relaciones subordinadas, cuando el texto verbal depende por completo de una serie plástica y la imagen misma interviene como el elemento necesario del texto (la publicidad, el cartel, los textos científicos y científico-técnicos).

Así, desde el punto de vista de la semiótica la presentación de los resultados de la actividad científica y de innovación es más oportuna en forma del texto con creolización completa que abastece la interacción de la información textual y gráfica y es condicionado por las propiedades psicofisiológicas de la percepción, expresándose en los siguientes aspectos:

- representa un íntegro reflejo de los objetos, fenómenos, situaciones y acontecimientos en sus relaciones y enlaces de accesibilidad sentimental temporal así como en el espacio;

- surge con la influencia directa de los irritantes físicos sobre las superficies receptores de los órganos de los sentidos;

- viene siendo la etapa necesaria del conocimiento, donde siempre de manera alguna esta vinculada al pensamiento, la memoria y la atención;

- se dirige por la motivación y tiene un cierto matiz afectivo-emocional;

- la elección elevada y la movilidad dejan la posibilidad de seleccionar de manera activa los elementos del material informativo adecuados a la tarea puesta;

- incluye la percepción visual, acústica, olfatoria, gustativa y táctil, además juega un papel importante en las sensaciones motrices, o cenestésicas, que regulan según el principio de la realimentación las relaciones recíprocas reales del sujeto con el objeto.
En el contexto del problema analizado se debe notar que la percepción está determinada por los factores individuales -las necesidades y los motivos- y factores que se refieren a los estímulos. En el gestaltismo de M.Vertheymerom y el S. Kellerem se destacan los siguientes rasgos de la percepción de la información [5]:

- la percepción simple del estímulo es más preferible si existe la posibilidad de la percepción difícil;

- se destacan los estímulos más fuertes, que forman la imagen, los otros elementos serán de fondo;

- la integridad de la percepción del objeto por falta de los elementos separados.

Así, el aspecto psicológico de la percepción de la información científica se caracteriza por la necesidad de creolización del texto científico - la presencia de imágenes es el estímulo para facilitar la percepción y la concentración de la atención sobre los aspectos más significativos del material presentado. Son preferibles los esquemas simples, los gráficos, los modelos, que distinguen los rasgos claves de los resultados científicos, los cuales corresponden a los intereses y a la motivación de la totalidad del público especifico y, sin tener en cuenta todos los detalles, son capaces de abastecer una íntegra percepción de la información propuesta.

En la teoría de la psicología se destaca el canal de prioridad de la percepción de la información por una persona, según el cual todas las personas están clasificadas en visuales (el canal prioritario es la vista), auditivos (el oido), kinestésicos (el tacto, el olfato, el gusto), digitales (opera la información simbólica). La estadística confirma la predominancia visuales y kinestésicos que es el estímulo adicional a la presentación de la información en la forma no verbal, incluso con el uso de las imágenes.

Tomando en consideración que existe una alta parte de auditivos y kinestésicos (cerca de $40 \%$ ), se ve la necesidad del aumento en la eficiencia de la influencia informativa y en los otros órganos de los sentidos que puede ser suministrado por medio de la visualización multimedia, como ejemplos pueden servir las instalaciones 4D y 5D, presentadas en exposiciones y en museos.

Como un modelo histórico brillante de la instalación multimedia puede servir la exposición del Museo de los vikingos (York, Gran Bretaña), donde se usa el efecto del retorno en la época de los vikingos con el uso de las figuras volumétricas y las imágenes, el audio-acompañamiento, los efectos táctiles y olfatorios. 


\section{Las formas modernas de la presentación de los proyectos de innovación.}

La información de las elaboraciones o invenciones más modernas pasa habitualmente a los encuentros de los científicos, presentaciones, exposiciones, conferencias, seminarios que cambia esencialmente los accesos a la presentación de la información, adelantando las nuevas exigencias: la compresión máxima y la eficiencia.

Los elementos básicos estructurales en la descripción de los proyectos de innovación son:

- El nombre del proyecto;

- La esfera de su aplicación y el público especifico;

- La actualidad e importancia del proyecto;

- El planteamiento del problema;

- La descripción breve de la solución técnica;

- Las ventajas ante los análogos;

- La argumentación económica de la oportunidad del proyecto;

- La propiedad intelectual;

- El estado actual del proyecto (la fase de ejecución).

Es oportuno tener en cuenta los siguientes principios psicolingüísticos en la formación de la parte descriptiva del proyecto de innovación:

1. No permitir la agrumeración de oraciones subordinadas, así como las oraciones con gerundio. Se puede fácilmente evitar tales defectos dividiendo toda la frase en frases más cortas y sustituyendo los participios por las formas personales.

2. No permitir que la enumeración pase de tres puntos cortos. Una lista excesivamente extensa hace la frase voluminosa, y la construcción sintáctica difícil y pesada, dificulta la comprensión y la memorización del contenido del texto.

3. Es necesario alternar las frases de la estructura sintáctica más difícil con las frases de la estructura mas simple. Se debe evitar la acumulación de frases con una alternación sintáctica parecida.

4. Para que la atención se activa le sirve también la comparación de opiniones opuestas. Además la apreciación de miradas opuestas debe seguir su exposición, y no precederlos.

Excepto los textos regulares y los datos numéricos, se crea y se distribuye activamente la información en forma gráfica, las GIS-TECNOLOGÍAS, animación, las 3D-presentaciones, audio, distintos sistemas interactivos etc., que permite influir al mismo tiempo sobre todos los órganos de los sentidos esenciales de la persona.
La eficiencia informativa de la información sobre el proyecto de innovación depende tanto directamente texto, como de la parte gráfica presentada en el mensaje.

Generalmente, en el aspecto no verbal de la información científica se cae la mitad del peso semántico. Las investigaciones de los psicólogos muestran que las personas perciben el resultado del siguiente modo [9]:

- Miran la ilustración;

- Leen el encabezamiento;

- Leen el comunicado mismo.

Se nota que el número de las personas, que leen los encabezamientos, superan en cinco veces el número de personas que leen el texto básico.

Así, en la preparación de la descripción de los resultados de la investigación se debe prestar atención especial a las ilustraciones y al nombre del proyecto de innovación. La formulación del nombre del proyecto debe contener el nombre del supuesto resultado con la indicación para el uso a las técnicas y tecnologías innovadoras.

El componente básico no verbal de la descripción del proyecto de innovación es la imagen (la foto, la ilustración, la estampa), que confirma la veracidad del mensaje verbal. Una buena fotografía en colores hace que la imagen se llene de emociones, causando una impresión viva de la presencia del espectador en la situación presentada. La foto da la realidad a la imagen. Los dibujos hechos con una técnica distinta, tienen también las ventajas, en ellos son posibles las exageraciones, efectos, el grotesco, fotografías inaccesibles (las presentaciones fantásticas), también los resultados de la modelación [11].

Como notan los especialistas, la ilustración atrae la atención, da la presentación sobre el objeto de la investigación, causa la impresión favorable que puede abastecer el criterio más alto en la apreciación de las descripciones técnicas de la innovación propuesta.

La creación y la instalación de las imágenes en las descripciones de los proyectos de innovación deben apoyarse en los rasgos de su percepción visual. Las investigaciones pasadas en diferentes ramas de la sicología, han mostrado la gran dependencia de los principios inconscientes en la percepción de la información (el ritmo, la simetría, el contraste, la proporción y así sucesivamente) de los rasgos individuales de la persona. 
El carácter expresivo en el gráfico se alcanza, a diferencia de los métodos lingüísticos, con la amplitud, el método de espacio abierto y el contraste de la imagen. La gráfica prepara, abre la percepción del lector al acontecimiento, -o sea al mensaje verbal, que debe ser breve, concretamente fundamentado y claro. Más abajo están presentados los aspectos básicos, que debe tomar en consideración a la formación de los componentes no verbales ilustrativos en las descripciones de los proyectos de innovación.

\section{Las características de la percepción de la composición [3]:}

- la vertical por falta de división - la inconmensurabilidad, la ligereza y el infinito;

- la vertical con el engrosamiento en la parte inferior con existencia de la base horizontal - la estabilidad;

- la horizontal - seguridad, la estabilidad, el movimiento y el desarrollo;

- la diagonal - la dinámica.

La composición construida sobre las horizontales y verticales precisas, se percibe con tendencia a la estabilidad, la estabilidad, y construida en las diagonales - al movimiento y los cambios. La composición horizontal se parecerá más sólida y pesada, que la vertical.

\section{Los rasgos de la percepción del color:}

- Los colores que estimulan y contribuyen a la excitación - rojo (volitivo, vivificante), anaranjado (caliente), amarillo (que contrasta);

- Los colores que tranquilizan -violeta (profundo), azul (que subraya la distancia), verde-azulado (variabilidad);

- Los colores pasteles que apagan los colores puros - rosado (tierno), color lila (cerrado), verde claro (cariñoso);

- Los colores estáticos, que equilibran otros colores púrpura (pretencioso), amarillo-verde (color que libera), verde puro (exigente, color que refresca);

- Los colores de tonos apagados - apagan la irritación y ayudan a concentrarse.

Según las investigaciones especiales es establecido que la cantidad de colores utilizados actúa directamente sobre la eficacia en la influencia del mensaje publicitario. Si la eficiencia de la percepción de la imagen en blanco y negro es del $100 \%$, la eficiencia bicolor se aumenta en 20 $\%$, y la multicolor - en un $40 \%$.

Los colores se dirigen a los sentimientos, y no a la lógica de la persona, es decir [9]:
- Provocan la reacción psicológica: subrayan la cualidad, el humor, el sentimiento, crean un ambiente cálido o frío; reflejan las épocas del año y etc.;

- Tienen consecuencias fisiológicas, como los irritantes ópticos positivos o negativos;

- Tocan sensaciones: la satisfacción, el aspecto exterior agradable;

- "Invocan" a los sentimientos: dan el volumen al ambiente y los artículos.

Los investigadores de la psicología de la publicidad, subrayan los siguientes colores más populares:

- Rojo en Rusia, Irak, México, Noruega;

- Anaranjado en Holanda;

- Amarillo en China;

- Verde en Austria, Bulgaria, México, Australia, Irlanda, Egipto;

- Azul en la India;

- Blanco en México;

- Castaño oscuro en Bulgaria.

Las formas de los objetos de percepción, que atraen la atención:

- los lugares de la acumulación densa de los elementos, que crean la impresión de masa;

- los elementos situados cerca y que influyen condicionalmente uno al otro ;

- la separación espacial por los puntos en caso de la predominancia de la instalación amorfa de los elementos;

- las combinaciones de los puntos que forman las figuras geométricas correctas o sus fragmentos.

Los gráficos son la forma eficaz de la presentación de los elementos no verbales en la descripción de los proyectos de innovación que presentan una dependencia funcional de indicios y se clasifican según su contenido:

1) Los que representan la dependencia de los cambios de los parámetros en el tiempo;

2) Los que representan el enlace de variables independientes y dependientes (u otras dos variables).

Los tipos clásicos de gráficos son el diagrama circular, el diagrama lineal, el gráfico, el histograma y el gráficopunteado, todos los otros diagramas (a excepción de las tarjetas) son sus derivadas. Según sea su objetivo y las tareas impuestas el proceso de la elección del diagrama se puede dividir en tres etapas:

1. La formulación de ideas, que se necesita llevar hasta el auditorio por medio del diagrama.

2. La definición del tipo de comparación de los datos, dis- 
puesto en el diagrama: de componentes, posicional, temporal, de frecuencia y correlativo.

3. La elección del tipo de diagrama, realizada con base a un cierto tipo de comparación.

Hay una serie de las recomendaciones simples para la construcción de gráficos, ofrecidas por L.V.Kulikov [7]:

1. El gráfico y el texto de manera mutua deben completarse mutuamente.

2. El gráfico debe ser claro "por sí mismo" e incluir todas las designaciones necesarias.

3. No es oportuno presentar sobre un gráfico más de cuatro curvas.

4. Las líneas en el gráfico deben reflejar la importancia del parámetro, las líneas esenciales son necesarias designarlas con cifras.

5. La inscripción sobre los ejes debe estar en la parte inferior izquierda.

6. Los puntos sobre las diferentes líneas hay que marcarlos con círculos, cuadrados y triángulos.

Al hacer los dibujos de innovación por medio de los gráficos para las descripciones de los proyectos es oportuno por medio de ellos presentar las características básicas tecnológicas cualitativas y cuantitativas en comparación con los análogos existentes que permitirá claramente demostrar las ventajas de la idea científica propuesta.

En total la visualización de los datos durante la descripción de las ideas de innovación debe responder a ciertos principios y postulados dominantes presentados más abajo [2].

1. La forma de la presentación del proyecto de innovación se refiere al resultado final visual del proyecto (la estructura, la imagen, el texto, el color, las variantes y los medios de la dirección de la interfaz) y prosigue de su funcionalidad, ella surge de la combinación de distintos elementos estructurales, pero nunca les corresponde. El grado de conformidad de la composición a las exigencias del consumidor puede ser revelado más a menudo de manera experimental.

2. Con la preparación de las ilustraciones para el proyecto de innovación es necesario la realización de la investigación de las necesidades concretas del cliente o el auditorio.

3. Cualquier proyecto de visualización de la información debe agilizar no sólo la comprensión, sino también el análisis de los datos en concordancia con ejemplos concretos de uso y por objetivos designados.
4. Para evitar la comprensión equívoca y la desfiguración de la información, siempre se debe citar la fuente y dar las referencias a las publicaciones, patentes, certificados registrados en la forma establecida.

5. La estética es una cualidad importante en los proyectos de la visualización de la información, pero ella siempre debe ser examinada como la consecuencia y nunca como el objetivo final.

6. La posibilidad básica de la visualización - transformar la información en los conocimientos, es necesaria también para la simplificación de la comprensión y la ayuda al conocimiento.

7. La visualización de la información es obligada a responder a los volúmenes crecientes de datos accesibles como un filtro cognitivo, la lupa de la comprensión. No debe pensar que cada visualización es el paso positivo adelante: la transferencia de datos simple en forma visual, que no verte luz al objeto representado, o que lo empeora, puede considerarse injustificada.

La aplicación de las tecnologías de la información con el avance de la producción científico-técnica abastece el tránsito a los métodos industriales y los medios del trabajo con la información, la posibilidad de su uso racional y eficaz. En este caso es oportuno usar las tecnologías multimedia - la combinación eficaz de varios tipos de información (el texto, la imagen, la animación etc.) en el portador electrónico, que se aplican con éxito en las exposiciones y con objetivos publicitarios en otras esferas.

La visualización multimedia es la presentación de la información de estudios hecha por medio de la pantalla, cuando su contenido pasa por las imágenes principalmente audiovisuales en la combinación con el hipertexto lacónico en la forma estético-emocional interactiva escenificada [11].

Este tipo de tecnologías de la información permite crear ediciones electrónicas (la presentación, los catálogos) en forma de una realidad virtual y abastecer la percepción eficaz de cualquier información en condiciones del régimen interactivo de la interacción. La ventaja importante de cualquier tipo de producción multimedia es la simplicidad y la accesibilidad al momento de trabajar con ella [10].

Dependiendo del procedimiento de la presentación de la información se distinguen los siguientes tipos de multimedia:

- los multimedia construidos sobre la interacción de diversos componentes informativos (el texto, los gráficos, el vídeo) por medio de las hipervínculos, que es el texto o la presentación gráfica especialmente formalizada, cuando cada uno de los hipervínculos conduce al bloque concreto informativo;

55 
- los multimedia establecidos en la interactividad que abastece al usuario la elección de la información necesaria, así como la sucesión y la velocidad de su presentación.

Entre las tecnologías más populares y eficaces de los multimedia usados al avance de la producción científicotécnica son: las presentaciones, las introducciones de pantalla y los catálogos de multimedia [5].

La presentación de multimedia es el único y más mo derno procedimiento de la presentación de la información científico-técnica en la actualidad, que incluye los materiales textuales, los dibujos, la fotografía, el show de diapositivas, la formalización sonora y el acompañamiento del locutor, la gráfica tridimensional, los video fragmentos y la animación [10].

La diferencia básica de las presentaciones de otros modos de la presentación de la información sobre las elaboraciones es su alta saturación informativa y la interactividad, es decir la capacidad de reaccionar en cierto modo a las acciones del usuario.

Las presentaciones son el medio de publicidad directa dirigida al usuario final, y llevan en él las propiedades del folleto electrónico o impresas, catálogo u octavilla al envío postal y la producción artesanal en el momento de la transmisión del disco compacto en las negociaciones de trabajo.

Tiene la posibilidad de reproducirlos independientemente y rápidamente en la medida de lo necesario, sin dirigirse a los servicios de las organizaciones extrañas, en la combinación con el bajo coste [1].

Es necesario notar la ancha difusión de las presentaciones multimedia entre las organizaciones científicas, ya que la información bien visualizada acompañada con las descripciones y las explicaciones, permite presentar las ventajas de las elaboraciones e interesar a los posibles socios [11].

El catálogo multimedia es una lista ordenada interactiva de las compañías, marcas, mercancías, servicios etc. con la descripción y la manifestación evidente de sus características básicas y las ventajas de multimedia: la síntesis sonora y de video, la información textual y gráfica, la animación, los gráficos dimensionales y tridimensionales, distintos efectos.

Los catálogos de multimedia permiten incluir en ellos mayor cantidad de la información, que los tipográficos y son el instrumento importante en las comunicaciones, que lleva en él la función informativa y es llamado a resolver las preguntas de los clientes acerca de las mercancías, trabajos y servicios propuestos por la compañía.

Los catálogos de multimedia incluyen los siguientes elementos [11]:

- la parte visual - es la ilustración, los textos, las fotografías, rollos de video y modelos de producción tridimensionales con la posibilidad de su viraje como también su ampliación y reducción;

- el contenido - son las descripciones minuciosas de las posiciones del catálogo y la información según las elaboraciones que lo acompañan, los materiales de salida, la compatibilidad etc.

La presentación visual correcta e impresionante y la alta velocidad del acceso a ella juegan un papel principal en la atracción del auditorio, por eso una de las tareas más importantes del aumento de la competitividad es el perfeccionamiento de la presentación de los proyectos de innovación en el espacio global de red, y como el método de su solución es el uso interactivo de la gráfica tridimensional [8].

La 3D-visualización - es la imagen tridimensional del objeto, incomparablemente más cualitativa y realista, que la foto o el vídeo, y este método lo usan en la arquitectura, en la televisión, en diversas presentaciones. El 3Dgráfico y animación permiten modelar cualquier objeto en la forma y el color completo, "vivificar" el dibujo, la casa, el automóvil o el edificio en el momento de construcción. Esta tecnología es capaz de visualizar el objeto desde todos los puntos de vista, aunque él exista solamente en forma de idea que es determinante a la hora de elegir cierto tipo de tecnología multimedia de presentación de la producción científico-técnica. La elaboración de la 3Dvisualización incluye la creación del modelo de objeto, la selección de la iluminación, la adición de foto- o vídeo elementos. El resultado es la imagen ideal del objeto en el escorzo necesario, en el ambiente del interior impresionante o el paisaje [5].

\section{El currículum vitae}

La presentación de la información sobre los proyectos de innovación deben apoyarse en la metodología fundamentada científicamente e incluir los elementos del texto creolizado. Los elementos no verbales llevan en la mayoría de los casos el peso básico semántico y facilitan la percepción de la información. 
La aplicación de las tecnologías de multimedia es justificada para la presentación de las elaboraciones científico-técnicas, permite, participando en la exposición o al encuentro con el socio, ceder la información completa y competente estructurada sobre la organización científica que es más fácil y más barato que la información similar en un formato impreso. Usando los distintos tipos de tecnologías multimedia, la organización científica puede ceder la elaboración, presentar el informe electrónico, modelar en el espacio tridimensional los objetos no existentes, es decir atraer la atención de los posibles socios e interesarlos en la cooperación posterior.

\section{BIBLIOGRAFÍA}

[1] El Web-estudio "Artena" / http://www.artena.ru/multimedia.

[2] La visualización de los datos y el diseño informativo/ http:// www.vmethods.ru.

[3] Elina E.A. Semiotika de la publicidad / http://lib.rus. ec/b/157063/read.

[4] Ermilova E.B. Visualización de la enseñanza como el medio de la formación de las capacidades de estudios / Autoreferencias de la tesis del PhD en ciencias pedagógicas. Kazan, 1999.

[5] El estudio de la experiencia de los países de la CEl por el uso de las tecnologías de la información modernas al avance de la producción científico-técnica a los mercados extranjeros / El instituto Bielorruso del análisis de sistema y el mantenimiento informativo de la esfera científico-técnica; El tutor del tema de N.A.Fomin. - Minsk, 2008. - 161 pag. - № ГP 20080938.

[6] Infografica en los ejemplos /http://www.dejurka.ru/graphics/ infographics-1.

[7] Kulikov L.V. La investigación psicológica: las recomendaciones metódicas de la realización. San Petersburgo.: Ciencia, 1994.

[8] Litkin I.I. Sistema de 3D visualizacion para el comercio electrónico// Innovaciones en la ciencia y la formación. - 2006. - №4.

[9] La psicología de la publicidad / http://www.adbusiness.ru/ content.

[10] Sidorova L.V. Ensedanza de los futuros pedagogos a diseñar los medios de la visualización multimedia para los estudios / Autoref. de la tesis del PhD en ciencias pedagogicas. Briansk, 2006.

[11] Shetko A.V. Tecnologías de multimedia en la presentación de la producción científico-técnica / http://belisa.org.by/ru/izd/stnewsmag/3_2008.

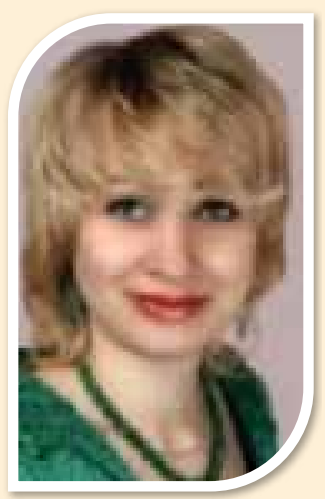

Maltseva Anna

Jefe de información científica y técnica y la organización del trabajo científico, de la Universidad Estatal del Suroeste, Kursk, Federación de Rusia

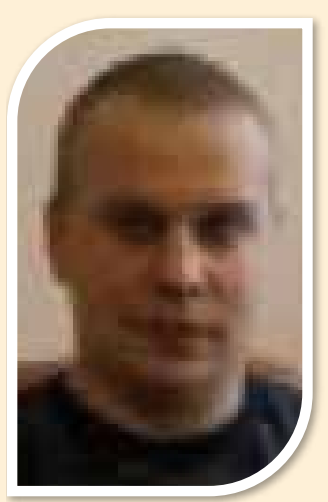

Frolov Sergio

Estudiante de doctorado, suroeste de la Universidad Estatal de Kursk, Federación de Rusia.

Cooperante en Investigación con el área de Posgrados de la UTE. 